\title{
Cardiac Resynchronization Therapy- Single center experience in Nepal
}

\author{
Roshan Raut', Man Bahadur KC ${ }^{2}$, Sujeeb Rajbhandari', Murari Dhungana', Mukunda Sharma², \\ Surakshya Joshi', Prashant Bajracharya'.
}

${ }^{1}$ Department of Cardiology, Shahid Gangalal National Heart Centre, Bansbari, Kathmandu, Nepal

${ }^{2}$ Department of Cardiology, Hospital of advanced medicine and surgery (HAMS), Dhumbarahi, Kathmandu, Nepal

Corresponding Author: Roshan Raut,

Department of Cardiology, Shahid Gangalal National Heart Center, (SGNHC),

Kathmandu, Nepal

E-mail: rautroshan@hotmail.com

ORCID ID NO: 0000-0002-4207-3932.

Cite this article as: Raut R., KC M. B., Rajbhandari S., et al. Cardiac Resynchronization Therapy- Single center experience in Nepal. Nepalese Heart Journal 2019; Vol 16 (2), 5-9

Submission date: $4^{\text {th }}$ September 2019

Accepted date: $18^{\text {th }}$ October 2019

\section{Abstract}

Background and Aims: Cardiac resynchronization therapy (CRT) has become an established treatment modality for patients with advanced heart failure. CRT abbreviates the dysynchronus heart failure mainly by correcting left ventricular dysynchrony. In the last three years, CRT has been regularly done in Shahid Gangalal National Heart Center(SGNHC) which has provided us the platform to report the outcome of CRT, for the first time in Nepal. The aim of this study is to review the recent clinical experience and outcome of CRT in our centre.

Methods: All consecutive patients who underwent CRT at SGNHC from July, 2016 to July, 2019 were reviewed retrospectively.

Results: Altogether 42 patients underwent CRT. Mean age was $65 \pm 11$ years (range 43 to 84 ). Coronary sinus cannulation was successful in 41 patients. In one patient, LV lead delivery was unsuccessful. Thus, procedural success was obtained in $95 \%$ (40 out of 42 ) patients. LV lead dislodgement occurred in three patients $(7 \%)$. Coronary sinus dissection occurred in two patients (5\%). Biventricular (BiV) paced QRS was significantly narrower compared to baseline QRS (127ms Vs $162 \mathrm{~ms}$, $\mathrm{p}<0.01$ ). During mean follow up of $12 \pm 10$ months (range 1 to 30 months), there was significant improvement in the clinical outcomes: NYHA class (1.8 Vs 2.9, p<0.01), LVEF (22.3 Vs 27.5, p<0.01), left ventricle internal diameter in systole (LVIDs), ( 57 Vs $60.5 \mathrm{~mm}, \mathrm{p}<0.01$ ). The CRT responder rate was $86 \%$. Super-responder was observed in $12 \%$ of patients.

Conclusion: In SGNHC, Cardiac resynchronization therapy is emerging as a routine treatment strategy with a reasonable efficacy and safety outcome.

Keywords: Biventricular pacing, Cardiac resynchronization therapy, Coronary sinus, heart failure.

DOI: https://doi.org/10.3126/njh.v16i2.26308

\section{Introduction}

Cardiac resynchronization therapy (CRT) has become the most recent advancement in the treatment of heart failure. CRT, also defined as Biventricular pacing, is defined as the simultaneous stimulation of both left and right ventricle. QRS delay $>120 \mathrm{~ms}$ is associated with increased mortality and morbidity in heart failure ${ }^{1}$. QRS delay, especially LBBB, and conduction delay impairs cardiac function by introducing intraventricular dysynchrony, AV dysynchrony and interventricular dysynchrony. CRT partially or totally corrects AV dysynchrony, interventricular dysynchrony and most importantly left ventricular dysynchrony ${ }^{2}$. The beneficial effect of CRT has been consistently proved in several randomized trials, like Miracle $^{3}$ (improves functional capacity and LVEF), REVERSE ${ }^{4}$ (improves LV remodeling), Care- $\mathrm{HF}^{5}$ (the first CRT trial to show survival benefit), and trials in combination with ICD like Companion ${ }^{6}$, MADIT-CRT ${ }^{7}, \mathrm{RAFT}^{8}$ (all showed survival benefit). Based on all these trials data, $\mathrm{ESC}^{9}$ and $\mathrm{ACCF} / \mathrm{AHA} / \mathrm{HRS}$ ${ }^{10}$ has endorsed guidelines for CRT. However, CRT is underutilized in eligible patients, with significant variation in age, gender, QRS duration, care provider, insurance status, and geographic location

(a) Nepalese Heart Journal. Nepalese Heart Journal retain copyright and works is simultaneously licensed under Creative Commons Attribution License CC - By 4.0 that allows others to share the work with an acknowledge of the work's authorship and initial publication in this journal 
of practices ${ }^{11}$ and so as in Nepal mainly due to unaffordability. And therefore, because of very small number of procedures, the outcome data of CRT therapy has never been reported in Nepal. In the last 3 years, CRT has been regularly done in Shahid Gangalal National Heart Center (SGNHC) which has provided us the platform to report the outcome of CRT for the first time in Nepal. The aim of this study is to review the recent clinical experience and outcome of CRT.

\section{Methods}

This is a retrospective observational study of all the patients who underwent CRT in SGNHC from July 2016 till July 2019. The data was collected from the procedural note, discharge note and the CRT logbook. The proforma of each patient was filled with the collected data and evaluated the baseline characteristics, the immediate outcome and the long-term outcome. The baseline characteristics included age, sex, cardiomyopathy type, LVEF, left ventricle internal diameter in systole (LVIDs), NYHA class, LBBB Vs non-LBBB, QRS width, device type, LV lead type and medication. The immediate outcome included procedural success, LV lead threshold; BiV paced QRS width and complications. The long-term outcome included improvement in NYHA class, improvement in LVEF and LVIDs during follow up period. The NYHA class was evaluated during 1 month and subsequent follow up in outpatient clinic and maintained in CRT logbook. Similarly, the LVEF and LVIDs was evaluated in 3-6 months, 6-12 month and then yearly and maintained in the logbook. For the practical purpose, the data (NYHA, LVEF and LVIDs) of the last follow up was included in the study (from 1 month to 30 months). Responder was defined as increase in LVEF by $>5 \%$ or increase in $>$ NYHA class I, with no HF admission or death ${ }^{12}$. Super-responder was defined as increase in LVEF by at least two-times or post CRT LVEF $>45 \%{ }^{13}$.

\section{Statistical analysis}

Continuous variable was expressed as mean \pm standard deviation or median and interquartile range if data was skewed. Categorical variable was expressed in percentage and compared with Chi Square. SAS software was used for statistical analysis. This study was approved by Institutional review board of SGNHC.

\section{CRT Implantation}

The usual CRT implant technique was as follows: Coronary angiogram was done to visualize the coronary sinus ostium and its branches. With the help of roadmap of coronary sinus ostium, coronary sinus (CS) was canalized with St. Jude non-deflectable decapolar catheter. Delivery guide was then advanced over the decapolar catheter and advanced in the coronary sinus main body just proximal to the target vessel. Coronory sinus angiogram was done to delineate the target vessel. The PTCA wire was then advanced to the target vessel and LV lead was then advanced over the PTCA wire to the target vessel. Capture threshold and diaphragmatic threshold were measured. Once optimum parameters were achieved, the sheath was slittered or peeled away and the LV lead was sutured in the prepectoral fascia. The RA and RV lead was then implanted and secured. All the leads were then connected to CRT device and secured in the pocket, which was closed in three layers.

\section{Results}

From July 2016 till July 2019, altogether 42 patients underwent for CRT. Baseline characteristics has been shown in table 1 .
Table 1: Baseline Characteristics

\begin{tabular}{|c|c|}
\hline Mean age in years (Range) & $65 \pm 11(43-84)$ \\
\hline \multicolumn{2}{|l|}{ Sex } \\
\hline Male & $27(64 \%)$ \\
\hline Female & $15(36 \%)$ \\
\hline \multicolumn{2}{|l|}{ QRS type/Rhythm } \\
\hline LBBB & $35(83 \%)$ \\
\hline RBBB & $1(3 \%)$ \\
\hline $\mathrm{CHB}$ & $6(14 \%)$ \\
\hline
\end{tabular}

Cardiomyopathy type

$\begin{array}{ll}\text { ICM } & 10(24 \%) \\ \text { NICM } & 32(76 \%) \\ \text { CRT upgrade for pacing } & 2(5 \%) \\ \text { induced cardiomyopathy } & \end{array}$

Functional Class

$\begin{array}{ll}\text { NYHA II } & 7(17 \%) \\ \text { NYHA III } & 29(69 \%) \\ \text { NYHA IV } & 6(14 \%)\end{array}$

Device Type

$\begin{array}{ll}\text { CRT-P } & 29(72 \%) \\ \text { CRT-D } & 11(28 \%)\end{array}$

LV lead Type

$\begin{array}{ll}\text { Quadripolar } & 38(95 \%) \\ \text { Bipolar } & 2(5 \%)\end{array}$

\section{Medication}

$\begin{array}{ll}\text { ACEI/ARB } & 40(95 \%) \\ \text { Beta-blocker } & 34(81 \%) \\ \text { Aldosterone antagonist } & 39(93 \%) \\ & \\ \text { Diuretics } & 42(100 \%)\end{array}$

Table 2: Procedural Outcome

\begin{tabular}{ll}
\hline Successful CS cannulation & $41 / 42(98 \%)$ \\
\hline Successful LV lead implant & $40 / 42(95 \%)$ \\
\hline Procedural success & $40 / 42(95 \%)$ \\
\hline CS dissection & $2 / 42(5 \%)$ \\
\hline LV lead threshold & $1 \pm 0.4$ V @ 0.4 ms \\
\hline LV lead dislodgement & $3(7 \%): 1$ readjustment unsuc- \\
& $\begin{array}{l}\text { cessful, 2 readjusted success- } \\
\text { fully, out of which 1 dislodged } \\
\text { again }\end{array}$ \\
\hline
\end{tabular}


Outcome measures

-Outcome measures were evaluated in 38 patients after excluding 2 unsuccessful CRT and 2 unsuccessful readjustments for LV lead dislodgment) as shown in table 3 .

-Mean Follow up duration was $12 \pm 10$ months (Range 1 to 30 months)

Table 3: Outcome Measures

\begin{tabular}{llll}
\hline Parameters & Pre-CRT & Post CRT & p Value \\
\hline QRS width (ms) & $162.4 \pm 16$ & $127.8 \pm 12$ & $<0.01$ \\
\hline LVEF & $22.3 \pm 5.5$ & $27.5 \pm 7.7$ & $<0.01$ \\
\hline NYHA class & $2.9 \pm 0.5$ & $1.8 \pm 0.6$ & $<0.01$ \\
\hline LVIDs(mm) & $60.5 \pm 9.6$ & $57 \pm 8.7$ & $<0.01$ \\
\hline Mitral regurgitation & $2.26 \pm 0.6$ & $2.03 \pm 0.3$ & $<0.01$ \\
\hline Responder by NYHA class & $33 / 38(86 \%)$ & \\
\hline Responder by Echo criteria & $20 / 34(59 \%)$ & \\
\hline Super-responder & $4 / 34(12 \%)$ & \\
\hline Heart failure admission & $2(5 \%)$ & \\
Mortality & $1(2 \%)$ & \\
Bi V paced & $99 \pm 0.2 \%$ & \\
\hline
\end{tabular}

\section{Discussion}

Baseline characteristics: In our study, $36 \%$ of female patients received CRT which is comparable with CRT landmark trials ${ }^{3,6}$. Given the incidence of congestive heart failure in women is almost similar to men $^{14}$, this number clearly shows that CRT has been underutilized in female patients, despite the fact that female patients even respond better than men $^{15}$.

Being our initial experience, we tried our best to put CRT in class I indicated patients to have better initial outcome. Therefore, based on ECG criteria, almost $85 \%$ of our patients had LBBB and around $12 \%$ had completed heart block with LV systolic dysfunction. Almost two-third of patients had non-ischemic cardiomyopathy (NICM) out of which 2 patients were upgraded to CRT due to the development of pacing induced cardiomyopathy. Most of the patients had NYHA class III symptoms, few were NYHA class II and ambulatory class IV symptoms. Regarding heart failure medicines, all patients were on diuretics, around $90 \%$ patients were on ACEI/ARB and aldosterone antagonists, whereas $80 \%$ were on beta-blocker. These data reflect that our CRT candidates have been properly managed with guideline directed medical therapy(GDMT). Two-third of our patients received CRT pacemaker whereas only one-third received CRT-defibrillator. This is in vast contrast with the real world data from other developed countries $^{16}$ where CRT defibrillator is far more common than CRT pacemaker. And its worthwhile to mention that affordability in our context is the key reason for not adding ICD in CRT pacemaker. With the growing evidence of better outcome with quadripolar lead as compared to bipolar lead ${ }^{17}$ and with our own learning curve, we implanted quadripolar LV leads in majority (95\%) of our patients.

Procedural outcome and complications: Coronary sinus cannulation was successful in 41 out of 42 patients. We were unable to cannulate coronary sinus in one patient because the coronary sinus size was small and could not clearly identify coronary sinus ostium in venogram. LV lead delivery was unsuccessful in another patient because we could not get the acceptable threshold in any of the available CS branches, probably due to extensive scarring. Hence, our procedural success was 40/42 (95\%), comparable to several previous studies $^{3,5}$. CS dissection occurred in two patients out of which we were able to successfully implant CRT in one patient whereas in other, due to extensive dissection with no visible target vessels, we had to reschedule the procedure after six weeks, which was then done successfully. LV lead dislodgment occurred in three patients; all of them occurred within one month of implant. LV lead readjustment was successful in two patients but one patient got LV lead dislodgement again and being planned for the $3^{\text {rd }}$ procedure with screw-in lead. We were unable to readjust the LV lead in the $3^{\text {rd }}$ patient, even with the screw-in lead, and he is being offered for surgical LV lead implant.

Outcome measures: Out of 42 patients, excluding two patients in whom CRT was unsuccessful and excluding other two patients in whom LV lead dislodgment was not fixed, outcome data has been assessed in remaining 38 CRT patients. The outcome data like LVEF and LVIDs were assessed only in 34 patients excluding four patients whose follow up duration was only one month. We routinely perform Echo only after three months post CRT implants.

BiV paced QRS was significantly narrower compared to baseline QRS (Pre CRT $162 \mathrm{~ms}$ Vs post CRT $127 \mathrm{~ms}, \mathrm{p}<0.01$ ). It has been shown in previous studies and meta-analysis that magnitude of QRS reduction predicts responder to $\mathrm{CRT}^{18}$. In our study, the reduction in mean QRS duration was $35 \mathrm{~ms}$, which is greater than previous meta analysis of CRT trials ${ }^{18}$. The greater reduction in QRS complex in our study was because majority of patient at baseline had LBBB pattern with QRS width more than $150 \mathrm{~ms}$. There was significant improvement in NYHA functional class with CRT (pre CRT 2.9 Vs post CRT 1.8), $(\mathrm{p}<0.01)$. Regarding the LV remodeling parameters, there was improvement in mean LV systolic function (Pre-CRT 22.3 Vs post CRT 27.5, p<0.01) and mean LV end systole diameter (LVIDs), (Pre CRT $60 \mathrm{~mm}$ Vs Post CRT $57 \mathrm{~mm}, \mathrm{p}<0.01)$. There was improvement in mitral regurgitation as well (pre CRT $2.2 \mathrm{Vs}$ post CRT 2.0, $\mathrm{p}=0.01$ ). These results are similar to other CRT trials and real world data ${ }^{3,19,20,21}$. CRT responder rate in the literature varies ( 32 to $91 \%$ ) due to various definitions of CRT responders ${ }^{22}$. Our CRT responder rate based on NYHA class was close to $85 \%$ which is very promising, likely because most of our patients were class I CRT eligible patients. However, when assessed by echo, the CRT responder rate was only $59 \%$ comparable to other real world data. Super-responder rates ranges from 13 to $16 \%$ in different studies ${ }^{23,24}$. In our study, super-responder rate was $12 \%$ (4 out of 34 patients). Those who super- responded to CRT were: one patientpacing induced cardiomyopathy, one patient- CHB with LV systolic dysfunction and two patients- NICM. In other words, all patients who super-responded to CRT were Non Ischemic Cardiomyopathy. Two patient had hospital admissions for heart failure and one patient died within one month of CRT.

Underutilization of CRT: Just to emphasis again, the beneficial effect of CRT has been consistently proved in several randomized trials, like Miracle $^{3}$ (improves functional capacity and LVEF), $\mathrm{REVERSE}^{4}$ (improves LV remodeling), Care- $\mathrm{HF}^{5}$ (the first CRT trial to show survival benefit), and trials in combination with ICD like Companion $^{6}$, MADIT-CRT ${ }^{7}$, RAFT $^{8}$ (all showed survival benefit). Despite the evidence base and guidelines, CRT has been underutilized in eligible patients, with significant variation in age, gender, QRS duration, care provider, insurance status, and geographic location of practices ${ }^{11}$. It is true for the underdeveloped country like Nepal where CRT is financially out of reach to most of the CRT eligible patients. Being a very small number of patient who undergo CRT, the CRT outcome had never been reported in Nepal before. As we have been routinely performing CRT in SGNHC for the last three years, this led an opportunity for us to report for the first time the outcome of CRT in Nepal. And our clinical outcome is comparable to other previous data. 


\section{Conclusion}

In SGNHC, Cardiac resynchronization therapy is emerging as a routine treatment strategy with a reasonable efficacy and safety outcome.

\section{Limitation}

The main limitation of this study is the small sample size. Being retrospective observational study, there is possibility of bias. Measuring Left ventricle end systolic volume (LVESV) would have been better as this is more reliable remodelling parameter than left ventricle internal diameter in systole (LVIDs). However, we do not routinely measure LVESV. We are planning to routinely measure LVESV in upcoming CRT implantations. Given small sample size and the nature of observational study, we cannot draw any conclusion regarding the improvement in hard endpoints like heart failure admissions and mortality.

\section{Sources of funding: None}

\section{Conflict of Interest: None}

\section{References}

1. Silvet H, Amin J, Padmanabhan S, et al: Prognostic implications of increased QRS duration in patients with moderate and severe left ventricular systolic dysfunction. Am J Cardiol 88(2):182-185, A6, 2001

https://doi.org/10.1016/S0002-9149(01)01619-8

2. Saxon LA, De Marco T, Schafer J, et al: VIGOR-CHF Investigators. Effects of chronic biventricular stimulation for resynchronization on echocardiographic measures of remodeling. Circulation 105(11):1304-1310, 2002. https://doi.org/10.1161/hc1102.105730

3. Abraham WT, Fisher WG, Smith AL, et al. Cardiac resynchronization in chronic heart failure. N Engl J Med 2002;346:1845-185

https://doi.org/10.1056/NEJMoa013168

4. Linde C, Abraham WT, Gold MR, et al. Randomized trial of cardiac resynchronization in mildly symptomatic heart failure patients and in asymptomatic patients with left ventricular dysfunction and previous heart failure symptoms. J Am Coll Cardiol 2008;52:1834-184

https://doi.org/10.1016/j.jacc.2008.08.027

5. Cleland JG, Daubert JC, Erdmann E, et al. The effect of cardiac resynchronization on morbidity and mortality in heart failure. N Engl J Med 2005;352:1539-1549 https://doi.org/10.1056/NEJMoa050496

6. Bristow MR, Saxon LA, Boehmer J, et al. Cardiacresynchronization therapy with or without an implantable defibrillator in advanced chronic heart failure. N Engl J Med 2004;350:2140-2150.

https://doi.org/10.1056/NEJMoa032423
7. Moss AJ, Hall WJ, Cannom DS, et al. Cardiacresynchronization therapy for the prevention of heart-failure events. N Engl J Med 2009;361:1329-1338. https://doi.org/10.1056/NEJMoa0906431

8. Tang AS,Wells GA, Talajic M, et al. Cardiacresynchronization therapy for mild-to-moderate heart failure. N Engl J Med 2010;363:2385-2395 https://doi.org/10.1056/NEJMoa1009540

9. 2013 ESCGuidelines on cardiac pacing and cardiac resynchronization therapy

10. $2012 \mathrm{ACCF} / \mathrm{AHA} / \mathrm{HRS}$ Focused Update Incorporated Into the ACCF/AHA/HRS 2008 Guidelines for Device-Based Therapy of Cardiac Rhythm Abnormalities

11. Curtis AB, Yancy CW, Albert NM, et al: Cardiac resynchronization therapy utilization for heart failure: findings from IMPROVE HF. Am Heart J 158(6):956-964, 2009. https://doi.org/10.1016/j.ahj.2009.10.011

12. Park MY, Alt man RK, Orencole M, et al. Characteristics of Responders to Cardiac Resynchronization Therapy: The impact of Echocardiographic Left Vetricular Volume. Clin Cardiol . 2012 December ; 35(12): 777-780 https://onlinelibrary.wiley.com/doi/full/10.1002/clc.22043

13. Natalia Antonio et al. Identification of super responders to cardiac resynchronization therapy: the importance of symptoms duration and left ventricular geometry Europace (2009) 11, 343-349 https://doi.org/10.1093/europace/eup038

14. Mozaffarian D, Benjamin EJ, Go AS et al. Heart disease and stroke statistics-2015 update: a report from the American Heart Association. Circulation. 2015;131:434-41.

15. Zusterzeel R, Selzman KA, Sanders WE et al. Cardiac resynchronization therapy in women: US Food and Drug Administration meta-analysis of patient-level data. JAMA Intern Med. 2014;174:1340-8. https://doi.org/10.1001/jamainternmed.2014.2717Masato

16. Fukunaga, MD; Kenji Ando, MD. Should We Include a Defibrillator for All Cardiac Resynchronization Therapy?Comparison of Cardiac Resynchronization Therapy Without and With Defibrillation -Circ J 2017; 81: 1768 - 1769. https://doi.org/10.1253/circj.CJ-17-0984

17. Mohit Turagam, Muhammad Afzal, Madhu Reddy and Dhanunjaya Lakkireddy. A META-ANALYSIS OF QUADRIPOLAR VERSUS BIPOLAR LEFT VENTRICULAR LEADS ON POST-PROCEDURAL OUTCOMES. JACC. Volume 67, Issue 13 Supplement, April 2016

https://doi.org/10.1016/S0735-1097(16)30776-8

18. Korantzopoulos, Panagiotis et al. Meta-Analysis of the Usefulness of Change in QRS Width to Predict Response to Cardiac Resynchronization Therapy. American Journal of Cardiology, 2016, Volume 118, Issue 9, 1368 - 1373 https://doi.org/10.1016/j.amjcard.2016.07.070 
19. Morani G, Gasparini M, Zanon F, et al. Cardiac resynchronization therapy-defibrillator improves long-term survival compared with cardiac resynchronization therapypacemaker in patients with a class IA indication for cardiac resynchronization therapy: Data from the Contak Italian Registry. Europace 2013; 15: 1273 - 1279.

https://doi.org/10.1093/europace/eut032

20. Marijon E, Leclercq C, Narayanan K, et al. Causes-of-death analysis of patients with cardiac resynchronization therapy: An analysis of the CeRtiTuDe cohort study. Eur Heart J 2015; 36: 2767 - 2776.

https://doi.org/10.1093/eurheartj/ehv455

21. Bogale N, Priori S, Cleland JG, et al. The European CRT Survey: 1 year (9-15 months follow-up results. Eur J Heart Fail 2012; 14: $61-73$.

https://doi.org/10.1093/eurjhf/hfr158
22. GERY TOMASSONI. How to Define Cardiac Resynchronization Therapy Response The Journal of Innovations in Cardiac Rhythm Management, 7 (2016), S1-S7 https://doi.org/10.19102/icrm.2016.070003

23. Castellant P, Fatemi M, Bertault-Valls V, et al. Cardiac resynchronization therapy: 'nonresponders' and 'hyperresponders'. Heart Rhythm 2008; 5:193-7 https://doi.org/10.1016/j.hrthm.2007.09.023

24. Gasparini M, Regoli F, Ceriotti C, et al. Remission of left ventricular systolic dysfunction and of heart failure symptoms after cardiac resynchronization therapy: temporal pattern and clinical predictors. Am Heart J 2008;155:507-14. https://doi.org/10.1016/j.ahj.2007.10.028 